\title{
DER NIBELUNGE NOTH UND DIE KLAGE
}

NACH DER ÄLTESTEN ÜBERLIEFERUNG

HERAUSGEGEBEN VON

KARL LACHMANN

VIERZEHNTER ABDRUCK DES TEXTES

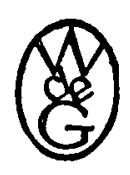

BERLIN UND LEIPZIG 1927

VERLAG WALTER DE GRUŸTER \& CO. VORMALS G. J. GÖSCHEN'SCHE VERLAGSHANDLUNG J. GUTTENTAG, VERLAGSBUCHHANDLUNG - GEORG REIMER KARL J. TRUBNER - VEIT \& COMP. 
